\title{
Preliminary results of dry Deep Soil Mixing soil-cement composite testing
}

\author{
Klaudia Jendrysik $^{1,{ }^{*}, \text { Monika } \text { Kiecana }^{2} \text { and Hubert Szabowicz }}{ }^{1}$ \\ ${ }^{1}$ Wroclaw University of Science and Technology, Wyb. Wyspiańskiego 27, 50-370 Wrocław, Poland \\ ${ }^{2}$ MENARD Polska Sp. z o.o. ul. Powązkowska 44c, 01-797 Warsaw, Poland
}

\begin{abstract}
This paper provides results of testing made for soil-cement mixtures in dry mixing technology. This technology is greatly dependent on existing soil condition; hence the results are of highly random nature. Material used in testing was distinguished with high organic content and low humidity. Tests were carried out in laboratory of Wroclaw University of Technology on 145 samples as ordered by Menard Polska Ltd. Company. Samples were prepared and stored under laboratory conditions and then, after various maturation time, were destroyed in a testing machine. The purpose was to determine the stress-strain curves used to find strength properties, strain at failure, modulus of elasticity, secondary modulus of elasticity versus cement content. Test confirmed improvement of soil strength properties after addition of cement binder. The results may be used to determine the most economic binder-to-soil ratio.
\end{abstract}

\section{Introduction}

Technologies available on the market allow the designer to place objects in difficult soil conditions [1-5], in areas with organic soils [6-10]. The easiest way to deal with this situation is to replace the soil. It is a beneficial treatment, because we can get a wellcompacted substrate with parameters chosen by the designer. However, when it is necessary at a large depth and surface, it ceases to be profitable. There is also a possibility of compacting the soil in various ways, depending on the existing conditions. The soil can be strengthened by making improvement by means of micropiles, soil nails or vertical columns [11]. Another option is to change the chemical composition of the soil by adding a binder. The bonding material may be cement, lime, ash or bentonite slurry. The binder is given wet or dry. The following article presents the properties of cement grout obtained by dry mixing.

The first mention of soil improvement by mixing the binder with the soil goes back to 1956. In the USA, Mixed in Place technology was created using a rotating mixer. This technology has been forgotten for a long time. Currently, an unquestionable pioneer in terms of technologies used and the area on which soil improvement was made is Japan. In Poland, the first deep wet mixing was made in 1999 in the Vistula embankments in

\footnotetext{
* Corresponding author: 216952@student.pwr.edu.pl
} 
Krakow. However, the first mass stabilization with dry mixing was made in May this year at the construction site of the S5 road section.

\section{Technologies based on dry mixed cement-soils}

\subsection{Deep Soil Mixing dry}

In Poland, performing dry DSM columns is not as popular as using this technology in wet conditions. This is due to the fact that it is only possible in soils with a minimum humidity of $60 \%$. In addition, cement strengths obtained during dry mixing are less than when using wet mixing. Nevertheless, the technology also has many advantages: it can be used in organic soils and is economically viable.

The works are carried out in the following steps:

- Input into the soil of the mixer, which includes a drilling rod

- Drive the mixer to the target column depth

- Lifting the rod upwards while simultaneously feeding and mixing the binder, transported by compressed air

- Performing inspections during the adding of the binder and after the column has been made
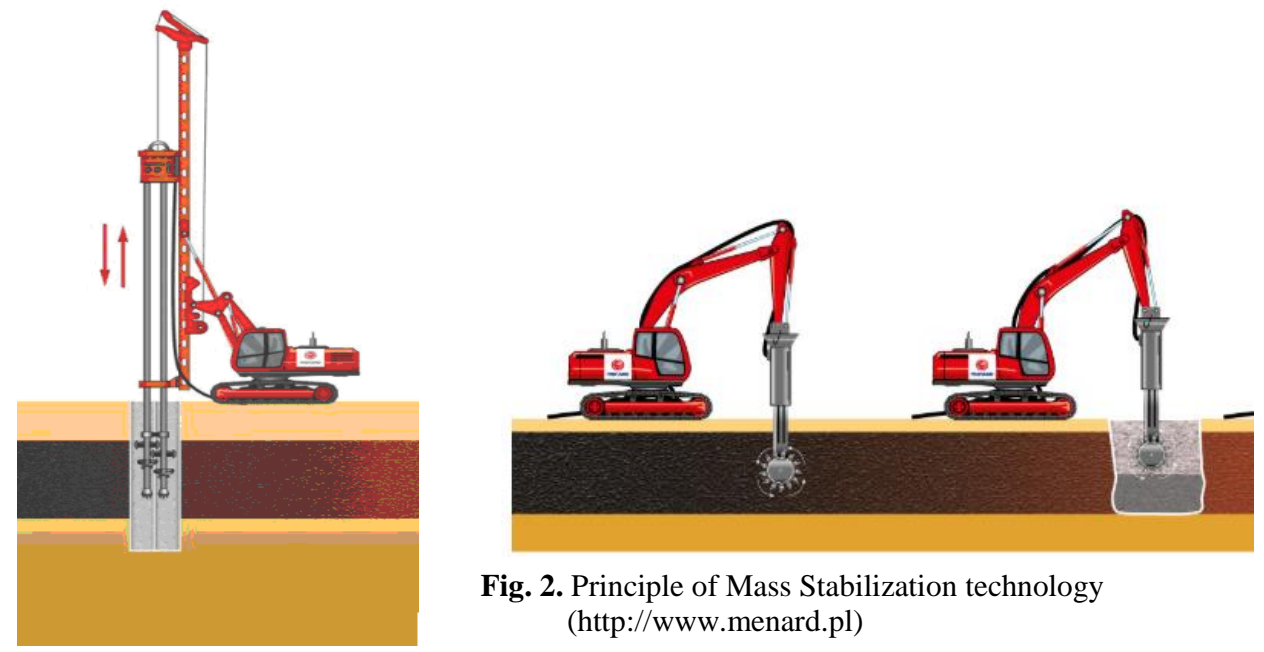

Fig. 2. Principle of Mass Stabilization technology (http://www.menard.pl)

Fig. 1. Principle of Deep Soil Mixing technology (http://www.menard.pl)

The binder is selected depending on the existing soil. It is recommended to clay and loam in plastic state use quicklime or lime with cement. In organic soils mixtures with the addition of blast furnace slags work best.

\subsection{Mass Stabilization dry}

Mass stabilization differs from DSM technology by the type of mixer. Strengthening is carried out in three stages:

- Input mixer into the soil with the destruction of its structure

- $\quad$ Simultaneous adding binder and mixing

- $\quad$ Repeated precise mixing 
The mixer can be inserted horizontally and vertically, depending on the needs. The mixing machine consists of:

- Mixing head, which is attached to the excavator and is designed to crush the soil and mix it with the binder

- A pressure feeder that feeds the binding agent using compressed air

- Control system placed in the operator's cabin, which allows to control the amount of binder given and obtain information on how much amount of binder was implemented in a given place

\section{Laboratory tests}

\subsection{Purpose and scope of the study}

The research was aimed at determining cement-soil parameters. In addition, the authors analyzed how the material behaves after destruction depending on the amount of binder (Fig. 3) and sample maturation time (Fig. 4) [12-15].

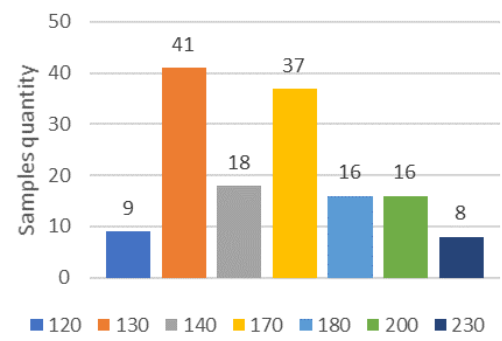

Fig. 3. The number of samples with a given cement content $\left[\mathrm{kg} / \mathrm{m}^{3}\right]$

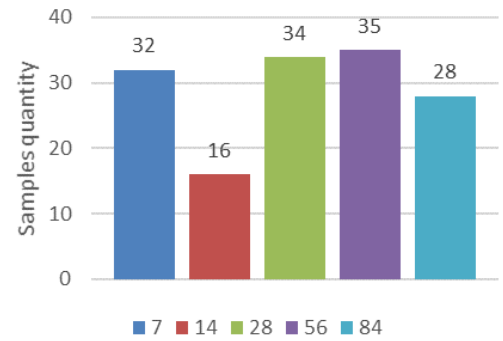

Fig. 4. The number of samples with various maturing time [days]

\subsection{Samples preparation and the course of the test}

The soil used for the research comes from the town of O1 awa, Lower Silesia province. Its natural humidity was determined, ranging from $37.4 \%$ to $56.2 \%$. The content of the organic parts was examined using the annealing method and it was found to be between $5.80 \%$ and $8.28 \%$. The soil was dry mixed with CEM IIIA 3.5 cement. Individual samples were differentiated due to the amount of added cement; it is within the limits of $120 \mathrm{~kg} / \mathrm{m}^{3}$ to 226 $\mathrm{kg} / \mathrm{m}^{3}$. The variables mentioned above were also natural moisture content and organic content mentioned above.

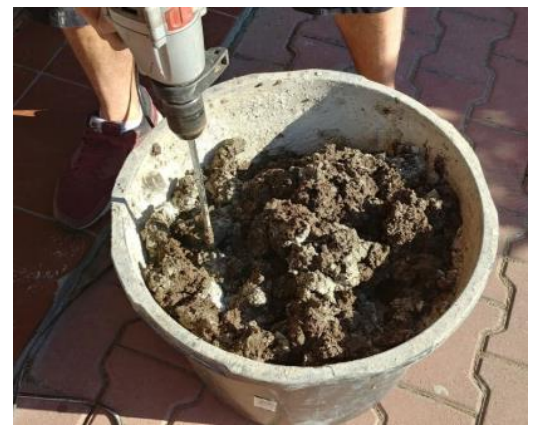

Fig. 5. Mixing of organic soil with dry

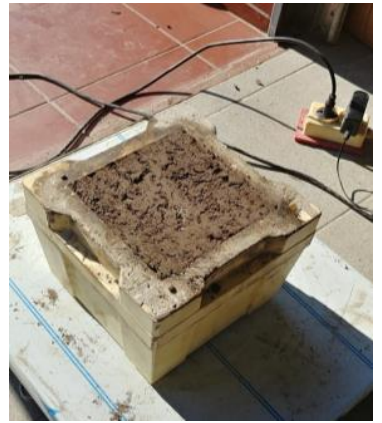

Fig. 6. Weighting of the cubic sample 
binder

The material was mixed in laboratory conditions until the binder was fully bonded to the soil. In order to provide comparable mixing conditions, high speed mixer was used (Fig. 5) instead of traditional laboratory mixer.

The soil and cement material was laid in standard forms with internal dimensions of $15 \times 15$ $\mathrm{cm}$, in four layers. Each layer was compacted under the pressure of $18 \mathrm{kPa}$. Over 145 samples were weighted (Fig. 6) and examined by means of mentioned compression test (Fig. 7). The sample weight varied from $4.46 \mathrm{~kg}$ to $5.80 \mathrm{~kg}$. The histogram of sample weight is given in Fig. 8. It must be underlined that sample density seems to be one of the crucial factors influencing compression strength and elastic modulus.

The samples were matured in standard temperature and humidity conditions. The obtained cubes were destroyed in the strength press after: 7, 14, 28, 56 and 84 days. In the testing process, the vertical displacement of the press piston caused by the given force was measured. From these values, the dependence of stress versus strain in the sample was determined, based on which the cement-soil strength was determined for uniaxial compression, Young's modulus $\mathrm{E}_{1}$ for $50 \%$ compressive strength and unloading-reloading modulus E2. The typical mode of destruction is presented on Fig. 9.

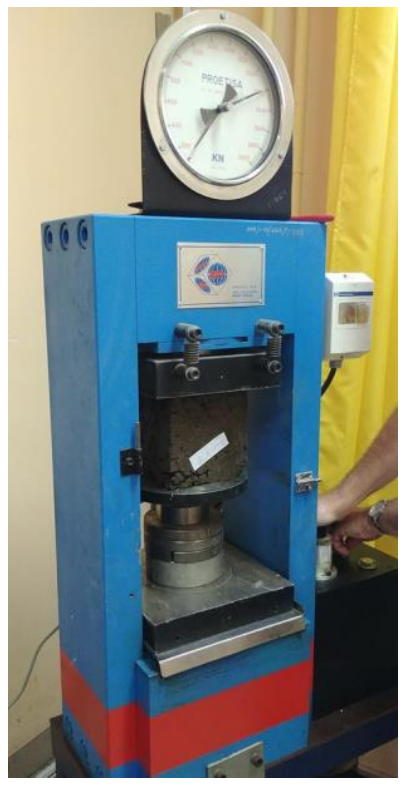

Fig. 7. PROETI compression machine

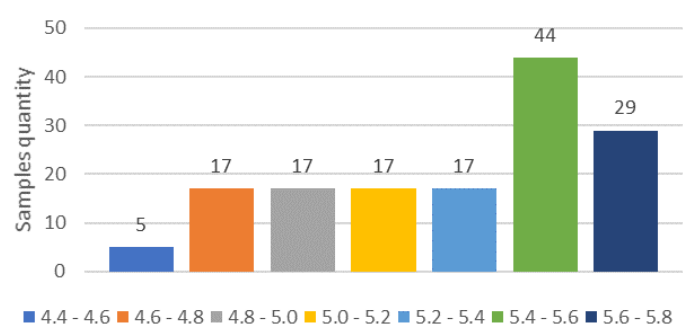

Fig. 8. The number of samples with various weight $[\mathrm{kg}]$

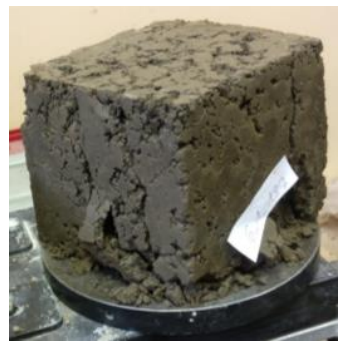

Fig. 9. Mode of destruction of dry soil-cement mixing

Exemplary stress-strain relationship and the range analyzed to determine elasticity modulus $\mathrm{E}_{1}(\mathrm{E} 50 \%)$ and $\mathrm{E}_{2}$ can be seen on Fig. 10. 


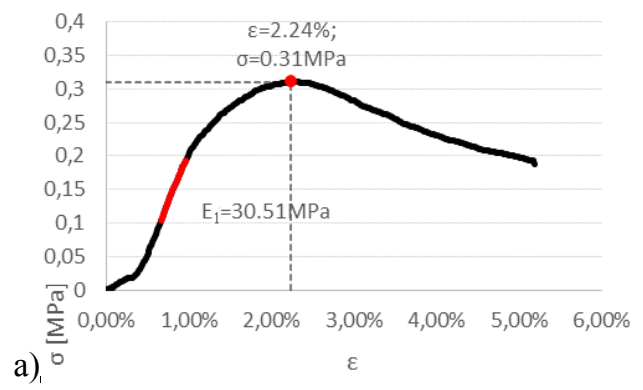

Fig. 10. Stress-strain relationship for simple testing

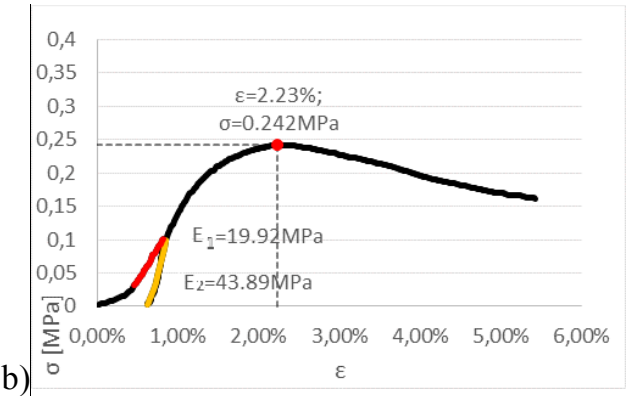

b) ${ }^{\circ}$

(a) and testing with unloading (b)

Calculations of elasticity modules were run in another way than the procedures used during testing the concrete samples. For the sake of stress-strain diagram nature, it was necessary to calculate the elasticity modulus $\mathrm{E}_{1}$ around $50 \%$ of strength (marked in red), instead of taking it over the section from 0 to $50 \%$. The reason of such nature of the diagram is matching up uneven sample to the press surface. At initial stage, the sample is compressed not on its full surface, which causes the error of curvature at initial part of the curve - the bedding error. Secondary modulus of elasticity $E_{2}$ was determined for 49 samples along the full section of secondary load application (marked in yellow).

\section{Test results}

\subsection{Cement amount - compression strength relationship}

Diagram 11 illustrates variation of medium strength of tested samples in MPa versus amount of cement in $\mathrm{kg} / \mathrm{m}^{3}$ for samples of maturation time from 7 to 84 .

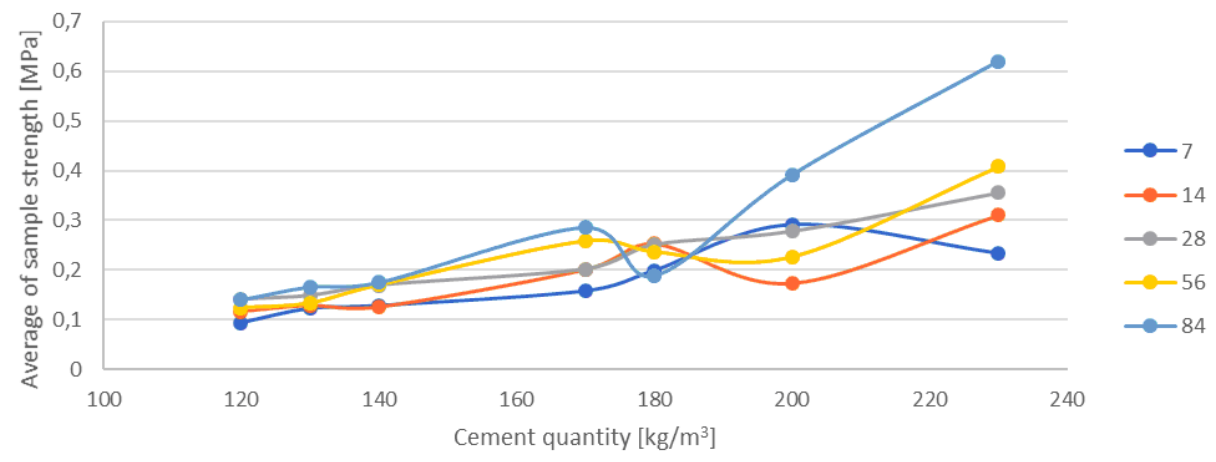

Fig. 11. Medium strength on the amount of cement for various maturation times

Along with higher cement content the strength is rising for all maturation times of samples. Independently of the maturation time, the samples with low cement content, 120$140 \mathrm{~kg} / \mathrm{m}^{3}$, featured small differences in compression strength. Its value was within 0.10 $0.15 \mathrm{MPa}$. A noticeable increase of compression strength was observed from cement content of $170 \mathrm{~kg} / \mathrm{m}^{3}$. Here apparent differences for particular maturation times $(0.15$ $0.30 \mathrm{MPa}$ ) are visible.

For cement content of $180 \mathrm{~kg} / \mathrm{m}^{3}$, a disturbance in increasing trend was observed. The 84-day samples had lower strength values due to their lower mass (the difference of about $10 \%$ ), hence also their consolidation. The highest increase and differences in strength 
between samples of various maturation times were revealed for cement content of 200-230 $\mathrm{kg} / \mathrm{m}^{3}$. The strength for these values varied from 0.17 to $0.41(0.60) \mathrm{MPa}$.

For cement content of $200 \mathrm{~kg} / \mathrm{m}^{3}$ another anomaly is found. The sample with 7-day maturation had much higher strength than sample tested after 28 days. These samples were of highest weight among all the tested, hence they were of highest thickening, so this could be the reason.

\subsection{Relationship between maximum material strain and cement content}

Research work included analysis of sample strain at destruction. The results of experiences are shown in diagram 12. For the sake of chaotic nature of above diagram we can hardly draw any clear conclusions. However, making use of simple linear regression, it was found that for each maturation time, in line with increase of cement content, the strain at destruction decreased. This means an increase of material stiffness. Also for increase of cement content, the variability coefficients of maximum strain went lower, hence the material gained more stable parameters.

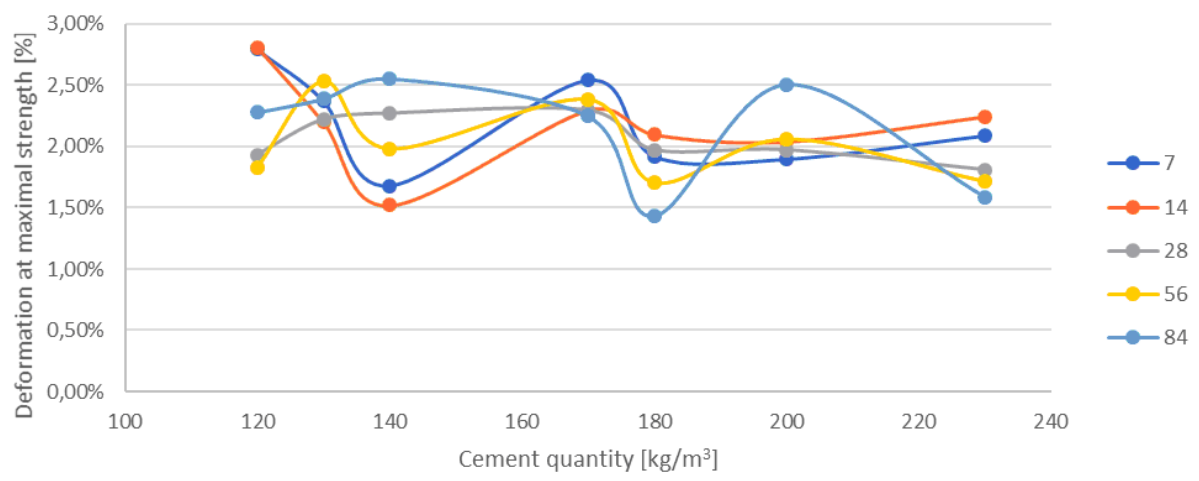

Fig. 12. Medium strength on the amount of cement for various maturation times

\subsection{Relationship of elastic modulus $E_{1}$ and cement amount}

The relationship between elastic modulus and cement amount for various maturation times of samples is shown in diagram 13.

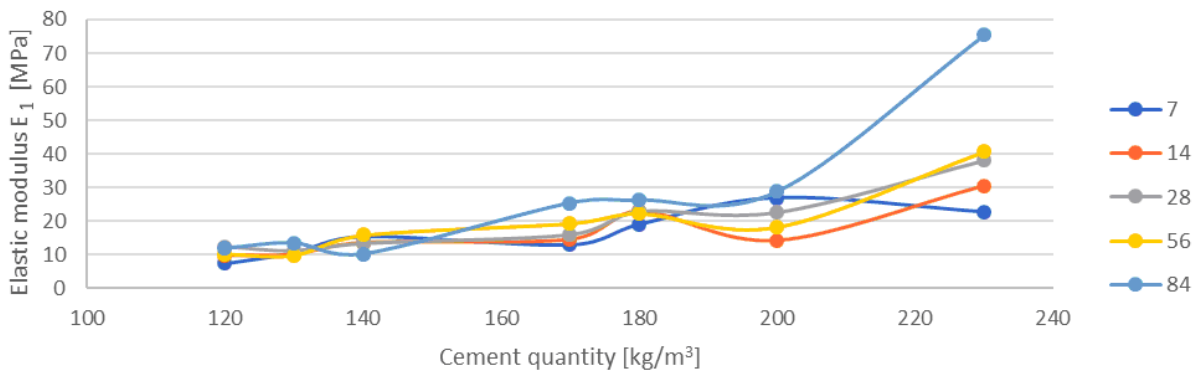

Fig. 13. Elastic modulus v. amount of cement for various maturation times

In case of small cement content, $120-140 \mathrm{lg} / \mathrm{m}^{3}$, the Young's modulus is between 7.5 and 15.5 $\mathrm{MPa}$, and the scatter is slight, like for compression strength, for particular maturation times. The next range visible in the diagram is $170-200 \mathrm{~kg} / \mathrm{m}^{3}$ with elastic modulus of 13.0 29.0 MPa. Here, for this range, there are considerable differences between successive 
maturation times. The largest increase of elastic modulus can be seen for the largest cement content of $230 \mathrm{~kg} / \mathrm{m}^{3}$. The observed values varied within the interval 22.7-40.7 MPa.

\subsection{Relationship between secondary elastic modulus E2 and cement content}

The relationship between secondary elastic modulus $\mathrm{E}_{2}$ and cement content for various maturation times is illustrated in diagram 14. As less number of samples were examined (49 out of all 145 under testing), unambiguous determination of ranges, as for diagrams 12 and 13 ) is impossible. A general increasing trend of elastic modulus at reloading for full range of cement content is noticeable. It is however worth noticing that rapid increase of secondary elastic modulus occurs above cement content over $170 \mathrm{~kg} / \mathrm{m}^{3}$. For most samples, the secondary elastic modulus $\mathrm{E}_{2}$ is from to 2.5 times higher than modulus $\mathrm{E}_{1}$ and takes the values from $19 \mathrm{MPa}$ to $100 \mathrm{MPa}$. Average values of the $\mathrm{E}_{2}$ to $\mathrm{E}_{1}$ ratio for particular cement content and maturation times are shown in diagram 14.

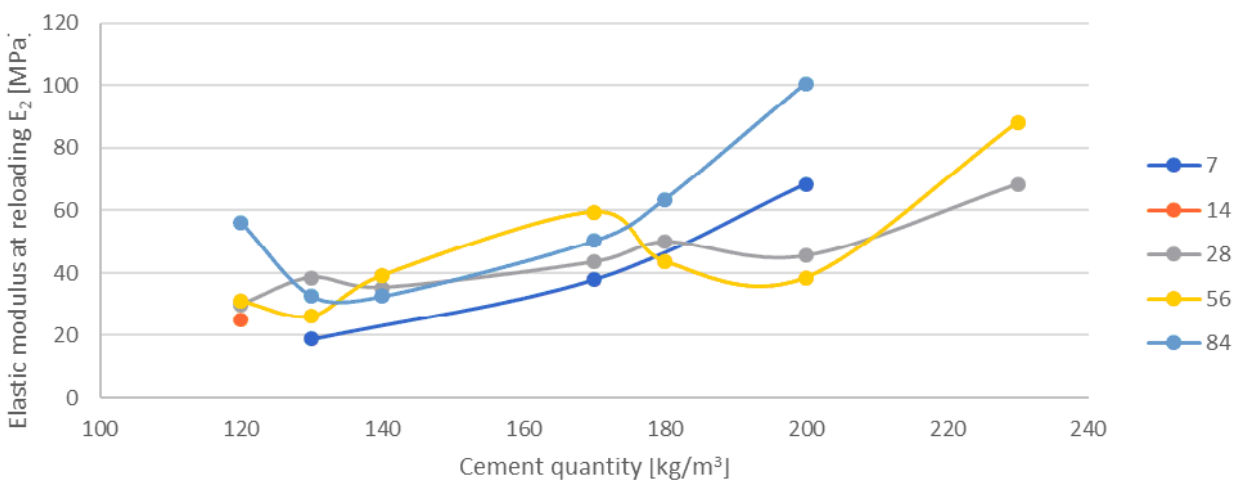

Fig. 14. Elastic modulus at reloading v. the amount of cement for various maturation times

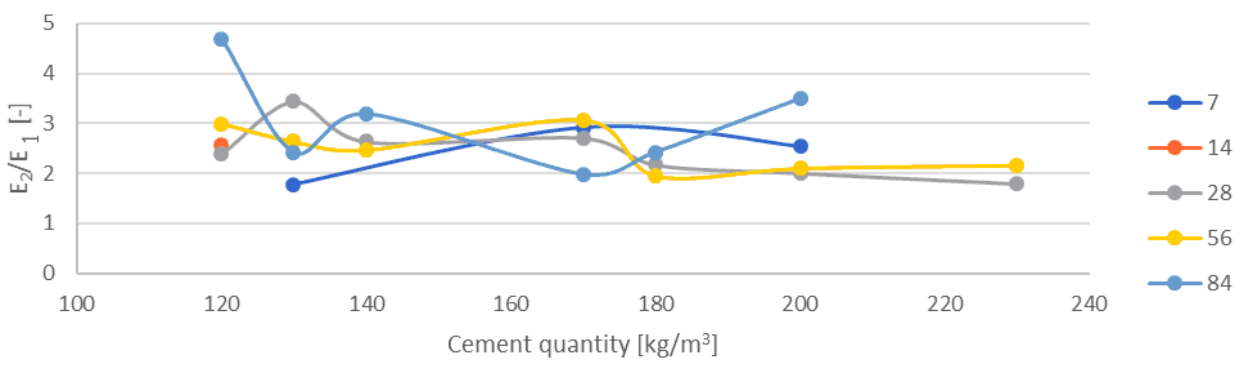

Fig. 15. $E_{2} / E_{1}$ ratio $v$. the amount of cement for various maturation times

\section{Conclusions}

In general, foundations should not be made in organic soils due to their variable properties over time and also under influence of water. As demonstrated by these tests, addition of a binder like cement allows improving strength properties of a soil. We can hardly determine proper cement to soil ratio due to random parameters of the latter. For the soils under examinations, the minimum addition of $170 \mathrm{~kg} / \mathrm{m}^{3}$ is that which provides a change which is visible and variable in time. However this depends strongly on humidity, organic content and condition of soil which is to subject to mass stabilization. Humidity will affect the ability of cement setting. If this ability is too low, all water could be bond, so organic content loose much of its volume causing a highly porous structure of weak properties. 
However, as resulted from above testing, appreciable improvement of strength could be achieved at just low humidity as $38 \%$, i.e. less than the limit of $60 \%$ referenced earlier. The condition of soil found in area covered by mass stabilization can have a very big impact on the soil-cement parameters achieved. More compacted material will obviously have better strength properties.

To sum up, increase of binder content leads to better soil-cement properties; however it should be born in mind that such material has very random properties dependent on many factors. Hence, economic application of DSM Dry technology may require detailed testing and supervision for each one project under design [16-18]. The above analysis was aimed at determining of cement-soil properties. It shows that: the more cement in the cement-soil, the greater its strength, the largest increase in adhesive strength can be observed in the initial stage of samples maturation, the higher binder content, the faster material degrades after damage, the maturation time of the sample has no significant effect on its behavior after damage.

The authors would like to address the gratitude to Faculty of Civil Engineering at Wroclaw University of Science and Technology for their kind assistance. Results will be used for a MSc diploma thesis and research grant no. $45 \mathrm{WB} / 0001 / 17$ - "Industrialized construction process (construction 4.0)"

\section{References}

1. P. Rychlewski, Wzmacnianie gruntów pod nasypami infrastruktury komunikacyjnej, GDMT, 52 (3/2018), 36-43 (2018) [in Polish]

2. P. Rychlewski, Wzmacnianie podłoża gruntowego pod inwestycje infrastrukturalne, Materiały budowlane, 547 (3/2018), 6-8 (2018) [in Polish]

3. A. Leśniewska, Strength and technological issues of soil improvement by means of Deep Soil Mixing Wet technology. Doctor's Thesis, Gdańsk University of Science and Technology, (2007) [in Polish]

4. M. Topolnicki, Design and execution practice of wet Soil Mixing in Poland, Int. Symp. on Deep Mixing \& Admixture Stabilization, Okinawa, 19-21 May, 195-202 (2009)

5. M. Topolnicki, General overview and advances in Deep Soil Mixing", XXIV Geotechnical Conference of Torino Design, Construction and Controls of Soil Improvement Systems, Torino, 25-26.02.2016, 1-30 (2016)

6. M.J. Timoney, B.A. McCabe and A.L. Bell, Experiences of dry soil mixing in highly organic soils. Proc. Inst. Civ. Eng. - Soil Improvement, 165, 3-14 (2012)

7. D. Piasecki, D, Stefaniuk, Micro-scale laboratory investigation of cement-soils composite, Stroitel'stvo-formirovanie sredy žiznedeâtel'nosti, Moskva, 27-29 aprilâ 2016. Moskva : NIU MGSU, 1061-65, (2016)

8. P. Kanty, J. Rybak and D. Stefaniuk, Risk related to deep soil mixing in organic soils, Integraciâ, partnerstvo $i$ innovacii v stroitel'noj nauke $i$ obrazovanii, 16-17 noâbrâ 2016, Moskva : NIU MGSU, 894-899 (2016)

9. P. Kanty, J. Rybak and D. Stefaniuk, Some remarks on practical aspects of laboratory testing of deep soil mixing composites achieved in organic soils, IOP Conf. Series: Mat. Sci. Eng., vol. 245, 022018 (2017)

10. I. Karpisz, J. Pyda, L. Cichy and D. Sobala, Study of the effect of cement amount on the soil-cement sample strength, IOP Conf. Ser.: Mat. Sci. Eng., 365, 042061 (2018)

11. M. Decky, M. Drusa, L. Pepucha and K Zgutova, Earth Structures of Transport Constructions, Scientific monograph, London: Pearson Education Limited, 180 (2013)

12. K. Brasse, T. Tracz, T. Zdeb \& P. Rychlewski, Influence of Soil-Cement Composition on its Selected Properties. MATEC Web of Conf., 163, 06006 (2018)

13. I. Karpisz, K. Jaworski, Study of compressive strength evolution in soil cement 
samples with fly-ash admixtures. IOP Conf. Ser.: Mat. Sci. Eng., 365, 032049 (2018)

14. A.A. Egorova, J. Rybak, D. Stefaniuk and P. Zajączkowski, Basic aspects of deep soil mixing technology control. IOP Conf. Ser.: Mat. Science and Eng., 245, 022019 (2017)

15. J.L. Chaumeny, P. Kanty, T. Reitmeier, Remarks on wet deep soil mixing quality control, XVI Danube - European Conf. on Geotechnical Engineering, 07-09 June 2018, Skopje, R. Macedonia, Paper No. 039, (2018)

16. M. Drusa, V. Chebeň and R. Bulko, New technologies implemented in geotechnical monitoring on transport constructions. Int. Multidisciplinary Scientific GeoConference Surveying Geology and Mining Ecology Management, SGEM, 2, 651-56 (2014)

17. D. Sobala, J. Rybak, Role to be played by independent geotechnical supervision in the foundation for bridge construction, IOP Conf. Series - Mat. Sci. Eng.-, 245 (2), 022073 (2017)

18. M. Drusa, J. Vlcek, Importance of Results Obtained from Geotechnical Monitoring for Evaluation of Reinforced Soil Structure - Case Study, Journal of Applied Engineering Sciences, De Gruyter Open, vol. 6. Issue 1 (2016) 